\title{
Idiomas cruzados
}

\author{
Jean-Pierre Castellani ${ }^{\bullet}$ \\ Université de Tours - Université Pascal Paoli
}

\section{Resumen}

Partimos de la premisa de que cualquier idioma es "otro", comenzando con la lengua materna que comenzamos a escuchar desde la gestación en el útero. La lengua materna es, por lo tanto, la primera lengua extranjera que aprendemos. Nos basaremos en las últimas conclusiones del trabajo realizado por investigadores en laboratorios de ciencias cognitivas y psicolingüísticas que subrayan la naturaleza híbrida de este aprendizaje de otros idiomas incluso antes del nacimiento del niño. La familia, la escuela, las diferentes situaciones históricas desarrollarán y modificarán estos logros. Cosmopolitismo, exilio político o económico, las decisiones individuales desempeñarán su papel. Es obvio que los escritores, en su elección voluntaria de escritura, son representantes activos de esas situaciones de doble pertenencia. Este fenómeno está particularmente presente en el caso de Francia con sus colonias y con la francofonía, y de España con la conquista de las Américas y la guerra civil de 1936 a 1939 que provocó un movimiento de exilio o de relación conflictiva con el terreno original. Sin entrar en los detalles de cada uno de estos ejemplos, tomaremos algunos, significativos de esta hibridación.

\section{Palabras clave}

- Identidad · Lenguaje · Madre · Doble · Bilingüismo · Cuerpo

\footnotetext{
- Jean-Pierre Castellani es profesor de universidad. Ha sido catedrático de Filología Hispánica en la Universidad de Tours y profesor asociado en la Universidad Pascal Paoli, (Córcega). Es vice-presidente de la SIEY (Sociedad Internacional de Estudios de Yourcenar) y miembro de la AICL (Asociación Internacional de los críticos literarios). Es autor de: Décrypter la presse espagnole, Collection Major, Paris, PUF, 2000, Goodbye Rabelais! figures libres \& Yourcenar, Almodóvar et Umbral..., Paris, EST, 2006 y de Je, Marguerite Yourcenar, d'un «Je» à «L'Autre», Paris, EST, 2011. Como coordinador-editor: Marguerite Yourcenar, une écriture de la mémoire, Sud, 1990; El embrujo de Shangai: Juan Marsé y Fernando Trueba, Nantes, Ed. du Temps, 2003; Goya en Burdeos de Carlos Saura, Nantes, Ed. du Temps, 2005; Texte et image dans les mondes hispaniques et hispano-américains, Tours, PUFR, 2007; Une enfance corse, Bleu-autour, 2010; Mémoire (s) de Corses, Colonna éd. 2016; Les utopies insulaires, Colonna éd. 2014; Écriture de soi et Autorité, Tours, PUFR, 2016; Portraits de Corses, figures emblématiques de la Corse d'aujourd'hui, Colonna éd. 2016; Corses de la diaspora, Scudo éditions, 2018. Colabora de modo regular en las revistas electrónicas Lecturas sumergidas en España y Diacritik en Francia.
} 


\section{Abstract}

This article is based on the premise that there is "otherness» in any language, which originates in our hearing of the mother tongue as early as during our gestation in the womb. The mother tongue is therefore the first foreign language we learn. We will base ourselves on the latest conclusions from the work carried out by researchers in cognitive and psycholinguistic science laboratories who underline the hybrid nature of language learning even before child birth. Family, school, different historical situations develop and modify this starting base. Cosmopolitanism, political or economic exile, individual decisions will play their role as well. It is obvious that writers, in their voluntary choice of writing, are active representatives of these situations of dual belonging. This phenomenon is particularly present in France's case of its colonies and the Francophonie, and in Spain with the conquest of the Americas and the civil war from 1936 to 1939 , which provoked a movement of exile or conflictual relationship with the original land. Without going much into, we will analyze a few significant examples that attest to this hybridity.

\section{Keywords}

- Identity · Language · Mother · Double · Bilingualism · Body

Me gustaría empezar con esta afirmación y esta convicción: el corso que soy solo puede ser sensible a este problema de doble identidad, lo que ahora llamamos «doble juego, doble yo». De hecho, siempre estamos atrapados entre dos identidades cuando nos encontramos como yo en un territorio complicado, entre isla y continente. Todos tenemos orígenes, identidades diversas que no son o no deberían ser, como dice Amin Maalouf «identidades asesinas» (Maalouf, 1998), porque las identidades lo pueden ser, desafortunadamente hoy en día en muchas partes del mundo, cuando tendrían que ser más bien identidades fértiles. El postulado que tomo es, por supuesto, el de una identidad constructiva, la que forja un camino, un hombre, un destino, comenzando primero por el lenguaje de la comunicación y posiblemente por la escritura. No es un punto de vista lingüístico sino más bien literario, o sociológico o estético.

Me gustaría tomar ejemplos y presentar reflexiones e incluso anécdotas para plantear este problema lo mejor posible. 
Primero, citemos a Enrique Vila-Matas, un gran novelista español, de origen catalán, que escribe y sigue escribiendo toda su obra en castellano. Regularmente, se refiere a la contestación que da a quienes lo cuestionan, con más o menos ironía o mala intención, sobre los motivos que lo empujan a escribir todos sus textos en el idioma de Cervantes. Explica esta elección de una manera muy sencilla: escribe en castellano para ser fiel a su madre quien le hablaba, durante su infancia, en catalán y le hizo jurar decir siempre la verdad. Entonces, cuando no miente, habla o escribe en catalán pero, como en sus obras de ficción, por naturaleza, inventa, finge, se siente obligado a escribir en español. Lo que parece paradójico, cuestionable o provocativo se vuelve finalmente muy lógico (Vila-Matas, 2002:24).

Otro ejemplo también puede ser significativo de esas diferentes estrategias lingüísticas según los idiomas aprendidos, practicados o elegidos: es el cantante vasco Paco Ibáńez quien dice que, por su parte, se siente vasco por la infancia, español por la escuela, francés por el exilio, italiano por gusto, judío por amistad.

El tercer ejemplo nos lo da el gran director de orquesta Daniel Barenboim, nacido en Argentina, de padre judío y ruso, educado en Israel y que trabaja principalmente en Alemania. Dice que se siente alemán cuando toca música alemana, italiano cuando dirige una orquesta italiana, austriaco cuando dirige una obra de Mozart. Él tiene, por supuesto, este refugio del que no hablaremos porque no es nuestro propósito, el lenguaje universal que es la música. No hay doble idioma en la música, los músicos usan un lenguaje universal que les permite expresarse en todas partes sin que haya una barrera de palabras. Otro comentario preliminar: los griegos llamaban bárbaros a todos aquellos que no hablaban su idioma, un fenómeno que se reproduce hoy con el uso generalizado del anglosajón. En esta perspectiva, todos los que no hablan inglés son tontos $\mathrm{y}$, en última instancia, el inglés permite no tanto la expresión de otra identidad sino la comunicación elemental y, a menudo pobre, entre todos aquellos que no hablan sus idiomas respectivos y con el inglés llegan a entenderse en todo el mundo.

La etimología de la palabra «bárbaro» muestra que se refiere a todo lo que parece extrańo, extranjero, ajeno, por lo tanto dudoso, malo, ambiguo. Esta tendencia al monolingüismo, ya perceptible entre los griegos, conduce a un lenguaje dominante y único, un lenguaje que excluye, crea fronteras, alimenta el racismo, provoca una situación de inferioridad.

Hay dos condiciones en las que el individuo se siente inferior, en una situación desagradable, debido a la lengua que no conoce, la del otro precisamente: la primera es la del turista que está en un país y que no entiende el idioma de la gente de este país y que se siente excluido. Lo más terrible que nos puede pasar es estar en un país cuyo idioma, o peor cuyo alfabeto no entendemos. En estos casos extremos, nos sentimos no solo idiotas sino excluidos, víctimas del rechazo, nos sentimos en otro lugar, no estamos realmente en el país, no podemos expresar nuestros sentimientos, estamos celosos de las personas que hablan. Vemos a nińos riéndose en la calle, adultos gritando en el metro, estamos molestos, queremos entrar en el juego, en su juego. Por mi parte, aunque hispanista, no me considero bilingüe y ocurre que en un jardín o en un lugar público, tengo celos de un niño que habla con fluidez mientras yo llevo cuarenta años tratando de dominar este idioma que no es el mío.

La segunda situación delicada y más dramática aún es la del emigrante que se encuentra en una situación de inferioridad diaria porque no entiende el idioma que se le habla y que no puede defenderse ni explicarse, está excluido, marginado, incluso humillado. 
Sin embargo, vamos a centrar nuestra atención no en personas anónimas como el viajero o el emigrante, sino en personas que intentan ofrecer textos escritos en un idioma que no sea su lengua materna. La lista de autores que podrían calificarse como escritores que hablan otro idioma es interminable. La bibliografía que ofrezco en el apéndice da fe de su variedad y riqueza.

Esto supone, sobre todo, un cuestionamiento sobre la realidad de este lenguaje que se dice materno. Es literalmente el lenguaje de la madre, es decir, el cuerpo de la madre. En el estado actual de nuestros conocimientos y prácticas científicas, el nińo nace del cuerpo de la madre, vive durante nueve meses en este cuerpo, respira allí, se alimenta allí, escucha, siente que este cuerpo late.

El idioma de la madre es el primer idioma del nińo, no es el del padre quien, en esta historia, en esta primera fase esencial, no es más que un elemento externo y puramente mecánico. Nunca hablamos de lengua paterna, nunca. El asunto se complica cuando la madre no existe o, al menos, debido a una muerte a pocos días del parto, no puede ejercer esta influencia primaria. Uno de los casos más famosos en la literatura es el de Marguerite Yourcenar: sabemos que, nacida de un padre francés y de una madre belga, Yourcenar no conoció a su madre quien murió unos días después de haberle dado a luz. El idioma de Yourcenar, aparte de los nueve meses de embarazo del que hablamos, es el de su padre, pero también el de las criadas que la cuidaron durante toda una infancia, ya que no fue a la escuela.

Sobre este tema, el periódico Le Monde publicó las conclusiones significativas de los trabajos muy serios realizados por investigadores del laboratorio de Ciencias cognitivas y psicolingüísticas del CNRS (Escuela de estudios superiores en ciencias sociales, EHESS, París) sobre las primeras percepciones de los recién nacidos. Una fórmula resume perfectamente estas observaciones: el discurso de la madre es una caricia. Según Viviane Chocas:

Au-delà de treize quinze semaines de gestation le foetus ne vit pas dans le silence il s'habitue à un environnement sonore où la voix de la mère émerge par-delà un singulier bruit de fond mêlant respiration, clapotis cardio-vasculaires et intestinaux. Son système auditif est fonctionnel dès la 25 e semaine ${ }^{1}$.

Durante los primeros meses de su vida, el bebé percibe diferencias entre el idioma de su madre y los otros idiomas e incluso distingue fácilmente dos idiomas extranjeros mostrando virtuosismo en estos ejercicios, al menos durante su primer año. Si se coloca a un bebé junto a mujeres que hablan diferentes idiomas, reaccionará con más emoción al escuchar el idioma de su madre y tendrá una percepción sensible del mismo: según el neurólogo Boris Cyrulnik: «Ce qui émerge pour le nouveau-né, c'est un morceau de la vocalité de sa mère»².

Es que de hecho los idiomas salen del cuerpo, solo entonces aprendemos vocabulario, sintaxis, gracias al cerebro. Se podría decir que el primer idioma extranjero que aprendemos es nuestro propio idioma, el que llamamos lengua materna. Sí, la lengua materna es un idioma que aprendemos; el niño escucha, imita, interpreta.

Encontraremos este fenómeno en todo el aprendizaje de lenguas extranjeras: cuando estudiamos un idioma, primero nos portamos como un actor, jugamos un juego, copiamos, repetimos expresiones lingüísticas y corporales, uno no tiene la misma voz, no tenemos las mismas entonaciones, en una palabra, no tenemos el mismo cuerpo, no somos los mismos, cambiamos de piel. Si hoy tuviera que hablar 
en español, estoy seguro de que no tendría la misma voz, la misma elocución, el mismo ritmo. Con el idioma del otro nos separamos, y el primer desdoblamiento es el de la lengua materna. Más tarde, las cosas pueden complicarse: primero, como lo ha demostrado Claude Hagège en sus libros, el cerebro humano, al contrario de las teorías de los centralistas de todas las tendencias, partidarios del lenguaje único, es capaz de recordar muchos idiomas de la misma manera que el disco duro de una computadora puede almacenar millones de datos (Hagège, 2000, 2006).

El traslado de un idioma a otro se hace naturalmente: todos los testimonios de niños nacidos de padres de diferentes nacionalidades ilustran este tipo de movimientos espontáneos entre el idioma del padre, el de la madre y posiblemente el del entorno escolar. En estos casos, a veces extremos, el niño habla con el padre usando su idioma y con la madre el suyo, y utiliza para sí mismo el que se le impuso en la escuela. A veces incluso el niño, de manera perversa, o en cualquier caso inteligente o irónico, usa un lenguaje diferente al del padre o de la madre para afirmar su independencia o su insatisfacción. En estos casos, hay una serie de juegos completamente originales, una representación, una comedia basada en la elección del idioma. Todos los que trabajan en Liceos franceses en el extranjero informan que si bien a los niños se les educa en francés en estos establecimientos, al mismo tiempo, cuando están en el patio de recreo, vuelven a su lengua materna. Sin saberlo, estos nińos se encuentran en esta situación de desdoblamiento que comentábamos antes.

Esta es la experiencia contada por Nancy Huston en un ensayo, Nord Perdu (1999) donde reconstruye su viaje entre el Canadá inglés donde nació y la ciudad de París donde se instaló para continuar sus estudios de literatura francesa, en la Sorbona. Cuando llegó a Francia, en los años 1970, hablaba un francés académico y, sin embargo, un poco más tarde, decidió — a pesar de ser básicamente una inglesa canadiense y no quebequense- escribir toda su obra directamente en francés. Al principio, ella no entendía todas las palabras del idioma corriente, no dominaba los códigos, a veces complicados, del francés y los que usan los franceses entre ellos. En esta perspectiva, leer y estudiar Nord Perdu debería ser obligatorio para cualquier futuro profesor de la lengua francesa, ya que está lleno de deliciosas anécdotas y reflexiones de interés. Además, para volver a la complejidad de los casos familiares de los que hablamos al principio, Nancy Huston se casó con Tzvetan Todorov, quien era su profesor en la Sorbona, de origen búlgaro, que escribió toda su obra teórica en francés. Sus hijos, nacidos en Francia, donde vive la familia, se encuentran entre los cruzamientos lingüísticos particularmente ricos a los que nos referimos. Por lo tanto, en ambos casos es una decisión libre, la de desplazarse a Francia y la de quedarse en este país, adoptando el idioma francés para contar historias de ficción como fue el caso de la novelista Huston o presentar análisis teóricos con Todorov.

Echemos un vistazo a las razones por las cuales un individuo que quiere ser escritor, o dicho de otro modo, cuya actividad principal es la escritura, elige un idioma distinto a su lengua materna para expresarse. El primero, que no es el principal a nuestro juicio, es el deseo de encontrar una audiencia más grande o nueva. Este es el caso hoy del angloamericano que permite el encuentro de un inmenso número de lectores en todo el mundo (pero también hay traducciones para lograrlo y no tiene nada que ver con el idioma de escritura, de creación). Así como un cantante de variedades como Julio Iglesias graba canciones en inglés para conquistar el mercado mundial, del mismo modo un joven escritor puede experimentar un deseo similar en el campo literario, pero este es un caso poco corriente 
de momento. La rápida traducción de los grandes éxitos permite precisamente esta conquista de la audiencia, y este argumento no es central en las decisiones de escribir en otro idioma. Actualmente no encontramos en inglés lo que se ha hecho durante mucho tiempo en francés, por razones históricas. El corpus que manejo se basa principalmente en un movimiento que va del extranjero al francés. De hecho, casi no hay transferencias transversales, del italiano al inglés, del portugués al castellano, del alemán al ruso, etc. Podemos citar algunos casos, bastante raros, como el ruso Vladimir Nabokov que escribió Trece cuentos: La veneciana y otros cuentos primero en inglés y en ruso, en los años veinte, y los publicó en francés en 1993 (Nabokov, Folio, 1993). Es lo que pasa también con el cubano Guillermo Cabrera Infante cuyo texto Holly Smoke se escribió primero en inglés (1985, Faber, London y Harper \& Row, New York) y luego se tradujo al español bajo el título de Puro humo (Alfaguara, 2000). El mismo Nabokov decía de sí mismo: «Je suis un écrivain américain, né en Russie, et formé en Angleterre où j’ai étudié la littérature française avant de passer quinze ans en Allemagne» ${ }^{3}$ (Nabokov, 1985:37).

Es necesario eliminar de estas prácticas la literatura en lengua francesa o incluso la de territorios anteriormente colonizados, que han adquirido su independencia en la segunda parte del siglo XX. Es cierto que esta decisión puede ser discutible pero me parece que está justificada en la medida en que la relación de una lengua materna con la lengua francesa no surge, con los francófonos o los ex colonizados, en los mismos términos lingüísticos y psicológicos, sociológicos o ideológicos que para otros.

Por supuesto, hay situaciones que surgen de diferentes circunstancias en el tiempo y el espacio. Una de las más conocidas es la del exilio político después de una guerra civil: este es el caso en España de Michel del Castillo, de padre francés y madre espańola o de Jorge Semprún. Ambos llegan a Francia muy jóvenes, apartados por los trastornos de la historia, de su tierra de origen. Su apellido ya es un programa lingüístico y humano muy complejo: Miguel se convierte en Michel y Jorge en Georges. Ambos siempre han escrito su obra en francés. Podemos considerar que Michel del Castillo es un escritor de lengua francesa porque no aguantaba lo que llama el griterío del discurso de Franco en la radio. Semprún ha publicado su primer texto en castellano en 1977, bajo el título Autobiografía de Federico Sánchez, pero publicó todas sus novelas en francés, a raíz de una situación de exilio, violencia, sufrimiento. No fue sino hasta 2003 cuando regresó al idioma español con Veinte años y un día, cuando tenía más de 80 años. El último texto fue traducido al francés por un traductor profesional, lo que confirmó relaciones extrańas con estos dos idiomas. Conocemos su destino único: refugiándose en Francia a los 14 años, fue a la escuela allí, luego, durante la guerra, fue encarcelado en un campo de concentración nazi, y tuvo una experiencia terrible allí que contaría incansablemente en sus narraciones. Vivió regularmente en París, excepto el período de 1988 a 1991, cuando ejerció el cargo de Ministro de Cultura en el gobierno de Felipe González.

Otro caso importante es el de un hombre mejor conocido como traductor que novelista y cuyo viaje se parece en parte al de Michel del Castillo o de Jorge Semprún: me refiero a Georges-Arthur Goldschmidt, quien informa y analiza, en un texto autobiográfico Le poing dans la bouche (2004), sus relaciones dialécticas con el idioma alemán, que es sin embargo su lengua materna, y que rechaza porque lo asocia con la propaganda hitleriana. Al igual que con Michel del Castillo, el no uso de la lengua materna se traduce por un rechazo de la ideología del nazismo en el caso de Alemania, del régimen de Franco con España: 
Le français avait quelque chose de mondain, de meublé, une langue pour tapisseries, médaillons et bergères. C'était une langue qui filait en bouche, qu'on pouvait prendre au coin des lèvres et qui passait toute seule. Elle n'avait pas les rondeurs ni les soulèvements de l'allemand ni ses douceurs ni ses duretés. L'allemand, ma langue maternelle, me prenait le corps autrement que le français, lequel était au-dessus, calé sur l'assise de l'allemand que, par honte de mes origines, je croyais pouvoir oublier. À dix ans, comme tout enfant allemand, j'étais en pleine possession de la langue puisque tout, en elle, est fait de ses propres éléments. On en est pénétré au plus intime de soi. Les bruits, les couleurs, les consistances, tout s'apprend dans l'émerveillement de la langue maternelle, la maison, le jardin ou l'école forment les sédiments de l'être-soi. (...) Il fallait lever le bras et ce cri de Heil Hitlaaa lacérait véritablement le corps de l'intérieur, le déchirait, c'était un cri de mort. Je n'y reconnaissais pas ma langue maternelle, si secrète et mélodieuse quand ma mère chantait ou me lisait le soir un conte de Grimm ${ }^{4}$. (Goldschmidt, 2009:15-16)

En todos estos casos podemos considerar que el escritor que adopta otro idioma vive o provoca una especie de renacimiento, se vuelve a bautizar a través de esta decisión, se trata de un idioma elegido y no impuesto. Una vez más, la lengua materna, no la elegimos, nos la impone el cuerpo de esta madre que nos hizo, concibió y nos dio a luz. Somos "traídos al mundo" como de una obra de teatro decimos que está "puesta en escena». Sí, el primer idioma extranjero que uno aprende es su lengua materna, y escaparse de él es un acto de libertad, una afirmación de independencia. Es una decisión adulta que adopta un nuevo idioma.

Los exiliados voluntarios, los exiliados políticos o económicos, por lo tanto, proporcionan un corpus de escritores extremadamente nutrido y variado que se expresará en un idioma que no sea su lengua materna.

Centremos nuestra atención en algunos casos ejemplares de esos diferentes caminos. Tomemos, por ejemplo, al griego Vassilis Alexakis, que es un caso espectacular de desdoblamiento o incluso triplicación de identidades. Como suele decir, afirma que tiene tres contestadores telefónicos en tres idiomas diferentes, muchas máquinas de escribir o teclados de computadora, tiene un departamento en Atenas y otro en París, navega de un idioma a otro, sin dolor ni trauma. Dice: «Le français m’apporte la distance et l'humour, je me relis plus sévèrement comme si c'était un autre» y añade "C'est fatigant d'avoir deux langues». También confiesa: "Je pars de chez moi pour aller chez moi» ${ }^{5}$. Escribe alternativamente en francés y en griego, incluso traduce en ocasiones, experimenta una especie de cruzamiento, de hibridación con esta doble identidad. Utiliza el idioma francés para las descripciones y el griego para los diálogos, juega con estos idiomas, básicamente, como lo hace un músico con su instrumento. Ha escrito un libro cuyo título lo dice todo: Les mots étrangers (Alexakis, 2002). Lo que explica que haya tomado la decisión de aprender otro idioma, una lengua africana, el sango, que va a practicar en el terreno. En este libro dedicado a palabras extranjeras, constantemente regresa a esta situación de desdoblamiento, de trastorno, cuando hablamos o escribimos una lengua extranjera.

Es evidente que hablar o escribir en otro idioma provoca una especie de excitación que analiza perfectamente Alexakis. Citemos algunas de las observaciones siguientes: «ma langue maternelle connaît mon âge» (Alexakis, 2002:54) o "apprendre une langue étrangère oblige à s'interroger sur la sienne propre» (Ídem, 77) o «quand j'apprenais le français j'écrivais tout ce que j'entendais dans les cafés, le métro et 
même chez les gens qui m'invitaient à dîner comme un reporter ou une secrétaire» (Ídem, 79) o «les grands dictionnaires m’agacent (...) ils m’étourdissent comme les grands magasins» (Ídem, 92) o "le caractère anodin des mots étrangers dispose au bavardage de la même manière que les monnaies dont on ignore la valeur pousse à la dépense». (Ídem, 112)

Es obvio que se manifiesta, a través de la escritura en un idioma que no es la lengua materna, otra relación con la escritura. Hay más libertad, locura, juego, disfrute, toma de riesgo, percibimos menos escuela, estándares, códigos, el autor puede regodearse, extenderse, inquietarse en este lenguaje híbrido.

El otro caso más reciente es el de las personas atrapadas entre dos idiomas, dos culturas o incluso dos religiones. Cierto número de ellos desfilan en un excelente programa de entrevistas de televisión llamado «Double je», con Bernard Pivot que no limita a sus invitados al campo de la escritura y elige sobre todo a personas más bien serenas: artistas, libreros, diversas personalidades, mientras que en el campo literario encontramos casos más dolorosos.

Hay un campo particularmente rico en este momento, el de toda una literatura escrita por escritores argelinos, a menudo mujeres, que se forman entre los dos idiomas, las dos culturas o religiones de los padres franceses o argelinos, entre el país de nacimiento y el país que los acoge, en una zona mediterránea atormentada desde hace mucho tiempo. Citemos, entre otros, el notable libro de Leila Sebbar Je ne parle pas la langue de mon père (2003) o Mes Algéries en France (2004) o Souâd Belhaddad con Entre-deux Je (2001) o Assia Djebar con La disparition de la langue française (2003) o Dalila Kerchouche con Mon père ce harki (2003). Todos están escritos en francés pero son dolorosos, como, por ejemplo, este fragmento de Souâd Belhaddad, en su libro Entre-deux Je (2001), que atestigua que adopta el idioma del país anfitrión, el del país dominante pero que se convierte en un idioma querido mientras que, en este ejemplo, la lengua materna se convierte en el lenguaje de lo prohibido:

Parfois ma mère reproche un peu la suprématie du «roumi», le français, à la maison. Mais c'est comme ça, je suis arrivée ici à cinq ans, j'ai toujours parlé cette langue, c'est celle qui s'est imposée, et voilà tout. Je lui assène cette réponse un peu fataliste, elle bat vite en retraite, le débat se clôt. Mais je mens, je le sais. Je mens. Parce que la vérité, c'est que l'arabe, ou plutôt l'algérien, est, pour moi la langue de l'interdit. La langue du «haram», péché, ce mot qui éclot en même temps que nous, c'est-à-dire dès notre naissance de petite fille. Toutes les petites filles musulmanes pourraient avoir ce mot comme second prénom. «Haram», le porc, l'alcool, la cigarette, les garçons, le maquillage, la minijupe, les boums, épouser un français. Certains de ces «haram » me sont indiscutables: le porc, l'alcool, d'accord ${ }^{6}$. (Belhaddad, 2001:58)

Y también este grito:

La langue algérienne, c'est aussi celle de la violence. Elle ne me berce jamais, comme dans mes premières années, lorsque ma nourrice faisait de l'arabe des senteurs de jardin. Mais ma nourrice n'est plus là et, depuis, cette langue rauque, quotidienne ne profère, le plus souvent, que des interdictions ou des menaces. (...) La langue arabe, en cette période, est comme le mot Algérie: encombrante, difficile, honteuse aussi lorsqu'un quelconque pitre de l'école se croit irrésistible en la mimant comme un vomissement, crachant des «rhâ, hâ », comme si ces consonances gutturales forçaient les frontières du palais, sans jamais le flatter. Je ne peux 
pourtant pas m'en passer. C'est la langue du dedans, comment me séparer de moi? J'en invente une autre. Celle de l'entre-deux je. Une fifty-fifty. Une moit-mot, comme on surnomme les enfants de mariages mixtes pour résumer la moitié de la France et celle de l'Algérie. Avec mes sœurs, je ponctue mes phrases de mots qui, à eux seuls, résument tout un état d'esprit: "Zamaa », par exemple, intraduisible «soi-disant», «Yainé», aussi intraduisible. J’aurais payé, alors, pour que ce mélange soit, comme aujourd'hui, une mode. Qu'au lieu de turpitude, les noms de "makrout, baklaoua» soient, au contraire, aussi mielleux que les gâteaux qu'ils désignaient. C'est terrible de ne pas habiter la langue de ses parents. Aussi terrible que de quitter leur pays ${ }^{7}$. (Belhadadd, 2001:58)

Así concebida, la lengua del otro se convierte en una lengua de libertad, de liberación, pero bajo ella subsiste siempre la lengua materna que nunca desaparece por completo, que palpita bajo la otra.

Hay otros casos más gozosos, como el escritor haitiano Dany Laferrière que en Pays sans chapeau (1999) proclama su necesidad de volver a su país de origen para escribir y encontrar allí sino la lengua de su madre, al menos la sensualidad de este territorio, indispensable para su creación. En un exordio titulado «Un escritor primitivo» justifica así este retorno a las fuentes:

Il y a longtemps que j'attends ce moment : pouvoir me mettre à ma table de travail (une petite table bancale sous un manguier, au fond de la cour) pour parler d'Haïti tranquillement, longuement. Et ce qui est encore mieux : parler d'Haïti en Haïti. Je n'écris pas, je parle. On écrit avec son esprit. On parle avec son corps. Je ressens ce pays physiquement. Jusqu'au talon. Je reconnais, ici, chaque son, chaque cri, chaque rire, chaque silence. Je suis chez moi, pas trop loin de l'équateur, sur ce caillou au soleil auquel s'accrochent plus de sept millions d'hommes, de femmes et d'enfants affamés, coincés entre la mer des Caraïbes et la République dominicaine (l'ennemie ancestrale). Je suis chez moi dans cette musique de mouches vertes travaillant au corps ce chien mort, juste à quelques mètres du manguier. Je suis chez moi avec cette racaille qui s'entre-dévore comme des chiens enragés. J'installe ma vieille Remington dans ce quartier populaire, au milieu de cette foule en sueur. Foule hurlante. Cette cacophonie incessante, ce désordre permanent — je le ressens aujourd'hui_ m'a quand même manqué ces dernières années. Je me souviens qu'au moment de quitter Haïti, il y a vingt ans, j'étais parfaitement heureux d'échapper à ce vacarme qui commence à l'aube et se termine tard dans la nuit. Le silence n'existe à Port-au-Prince qu'entre une heure et trois heures du matin. L'heure des braves. La vie ne peut être que publique dans cette métropole étonnamment surpeuplée (une ville construite pour à peine deux cent mille habitants qui se retrouve aujourd'hui avec près de deux millions d'hystériques). Il y a vingt ans, je voulais le silence et la vie privée. Aujourd'hui, je n'arrive pas à écrire si je ne sens pas les gens autour de moi, prêts à intervenir à tout moment dans mon travail pour lui donner une autre direction. J'écris à ciel ouvert au milieu des arbres, des gens, des cris, des pleurs. Au cœur de cette énergie caribéenne. Avec une cuvette d'eau propre, pas trop loin, pour me rafraîchir le corps (le visage et le torse) quand l'atmosphère devient insoutenable. L'air irrespirable. L'eau gicle partout. Denrée rare. Après cette brève toilette, je retourne à grandes enjambées vers ma table bancale pour me remettre à taper comme un forcené sur cette machine à écrire qui ne m’a jamais quitté depuis mon premier bouquin. Un vieux couple. On a connu des temps durs, ma vieille. Des jours avec. Des jours sans. Des nuits fébriles. Curieusement, c'est une machine qui m’a permis d'exprimer ma rage, ma peine ou ma joie. Je ne crois pas que ce soit uniquement une machine. Des fois, je l'entends gémir quand elle sent que je suis triste, ou grincer des dents quand elle entend 
gronder ma colère. J'écris tout ce que je vois, tout ce que j'entends, tout ce que je sens. Un vrai sismographe. Subitement, je lève la Remington à bout de bras vers le ciel net et dur de midi. Écrire plus vite, toujours plus vite. Non que je sois pressé. Je m’active comme un fou, alors que, autour de moi, tout va si lentement. Je finis à peine une histoire qu'une autre déboule. Le trop-plein. J'entends la voisine expliquer à ma mère qu'elle connaît ce genre de maladie. -Oui, chère, depuis qu'il est arrivé, il passe son temps à taper sur cette maudite machine.

-Il parait, dit la voisine, que cette maladie ne frappe que les gens qui ont vécu trop longtemps à l'étranger.

—Est-ce qu'il est devenu fou? demande anxieusement ma mère.

—Non. Il lui faut simplement réapprendre à respirer, à sentir, à voir, à toucher les choses différemment.

La voisine ajoute qu'elle connaît un remède qui pourrait m'aider à retrouver un rythme normal. Je ne veux pas de thé calmant. Je veux perdre la tête. Redevenir un gosse de quatre ans. Tiens, un oiseau traverse mon champ de vision. J'écris: oiseau. Une mangue tombe. J'écris : mangue. Les enfants jouent au ballon dans la rue parmi les voitures. J'écris: enfants, ballon, voitures. On dirait un peintre primitif. Voilà, c'est ça, j'ai trouvé. Je suis un écrivain primitif ${ }^{8}$. (Laferrière, 1997:11-14)

Volvemos a encontrar en este hermoso texto la proclamación que las relaciones con la lengua son físicas y sensuales antes de ser racionales.

Por su parte, François Cheng es chino, aprende el francés relativamente tarde y rápidamente siente pasión por este idioma, que relata en un libro bajo el título significativo de Le dialogue, del cual saco esa declaración de amor:

Le destin a voulu qu’à partir d'un certain moment de ma vie, je sois devenu porteur de deux langues, chinoise et française. Était-ce tout à fait dû au destin? À moins qu'il y entrât tout de même une part de volonté délibérée? Toujours est-il que j'ai tenté de relever le défi en assumant, à ma manière, les deux langues, jusqu’à en tirer les extrêmes conséquences. Deux langues complexes, que communément on qualifie de "grandes ", chargées qu'elles sont d'histoire et de culture. Et surtout, deux langues de nature si différente qu'elles creusent entre elles le plus grand écart qu'on puisse imaginer. C'est dire que, durant au moins deux décennies après mon arrivée en France, ma vie a été marquée par un drame passionnel fait avant tout de contradictions et de déchirements. Ceux-ci, toutefois, se sont transmués peu à peu en une quête non moins passionnelle lorsque j'ai opté finalement pour une des deux langues, l'adoptant comme outil de création, sans que pour autant l'autre, celle dite maternelle, soit effacée purement et simplement. Mise en sourdine pour ainsi dire, cette dernière s'est transmuée, elle, en une interlocutrice fidèle mais discrète, d'autant plus efficace que ses murmures, alimentant mon inconscient, me fournissaient sans cesse des images à métamorphoser, des nostalgies à combler. Rien d'étonnant à ce que depuis lors, au cœur de mon aventure linguistique orientée vers l'amour pour une langue adoptée, trône un thème majeur: le dialogue. Ce thème a illuminé mon long cheminement; il m’a procuré maintes occasions d'exaltation et de ravissement chaque fois que la symbiose patiemment recherchée se réalisait comme par miracle, une symbiose qui, en fin de compte, m'a porté et continue à me porter bien plus loin que ce que je pouvais présager au départ ${ }^{9}$. (Cheng, 2002:7-8)

Por lo tanto, podemos ver que el problema del idioma del otro no surge en términos de exclusión o antagonismo en estos casos, o de muerte de uno de los dos idiomas. Además, cada vez que Bernard Pivot preguntaba, en sus famosas 
entrevistas, las preguntas esenciales: ¿̨en qué idioma sueñas, en qué idioma escribes cartas de amor o un texto de ficción, en qué idioma hablas de comida, comentas la política, en qué idioma insultas? las personas en situaciones de doble-yo contestaban de modo distinto según los interlocutores, las circunstancias, los destinatarios.

El idioma es, en ese momento para quienes hablan o escriben, como la música para el músico que dispone de notas para componer. Es una riqueza tener varios idiomas para expresarse, incluso para expresar el dolor. Se sabe que los dos tercios de los nińos en el planeta se crían en un entorno donde se practican dos idiomas. El otro idioma o el idioma del otro no es criminal, el idioma adoptado no mata al primero, el primer idioma, la lengua materna nunca desaparece como las páginas que escribimos en la computadora que creemos perdidas pero que siempre encontramos en el disco duro. La lengua materna siempre correrá debajo, influirá en la otra, la nutrirá. Es el escritor marroquí Edmond Amran El Maleh quien dice: "J'ai écrit en français, mais avec cette hésitation qui fait que la langue arabe est là, en dessous, qui pousse, qui accélère le rythme et qui, finalement, donne quelque chose de nouveau» ${ }^{10}$.

Esta fascinante experiencia no es exclusiva de los escritores: los trabajadores migrantes también la conocen a su manera y se convierten en otros al hablar el idioma del país de acogida.

Sin embargo, cuando tocamos el campo de la escritura literaria, cuando pasamos de un lenguaje de comunicación a un lenguaje de creación, esta experiencia es una riqueza. El francés, el inglés o el ruso de quienes adoptan otro idioma es un lenguaje más complejo y más barroco, nacido de este tipo de embriaguez, impregnación y distancia, libertad que no depende de la escuela. Escritores como Héctor Bianciotti, Jorge Semprún, Emile Michel Cioran, Samuel Beckett, Gabriel D’Annunzio, Michel del Castillo o Agustín Gómez Arcos, crean en otro idioma que conduce a una doble identidad de la escritura.

La adopción, como se dice a propósito de la de un niño, de otro idioma influye, en última instancia, en la identidad, es una búsqueda de identidad, una conquista de identidad, un enriquecimiento de identidad. No es la manifestación de una falta o de una perturbación o de una marginación, lo que sería la característica de los bárbaros como decían los griegos, de las personas enajenadas en el primer sentido del término, es decir, convertirse en otro, pero al contrario de la voluntad de las personas que logran proporcionarnos obras románticas, teóricas e históricas. No digo poéticas voluntariamente, porque se puede notar que hay pocos movimientos transversales en poesía, excepto quizás los raros ejemplos de Paul Celan o Tristan Tzara. Son pocos poetas los que pasan de un idioma a otro y cambian de tonalidad, son más bien los novelistas o dramaturgos quienes experimentan este fenómeno. Así es como la mayoría de los grandes poetas españoles exiliados después de la Guerra Civil mantuvieron el idioma español en sus obras para escribir sus obras, sea Jorge Guillén, Emilio Prados o Rafael Alberti. Es cierto que se puede argumentar que los primeros se encontraron en unos países anfitriones que utilizaban el mismo idioma que su lengua materna, pero Alberti vivió en Italia, y, sin embargo, continuó creando su poesía en español, nunca en italiano, idioma del país anfitrión durante tantos años. Una de las posibles explicaciones proviene del hecho de que la poesía está demasiado vinculada al cuerpo, a los sentidos, al ego inconsciente y profundo, que dice una intimidad física que solo la lengua materna puede expresar. Pero no es más que una hipótesis... 
Por supuesto, estas son solo algunas pistas, muchas preguntas y algunas respuestas, porque el tema está lejos de agotarse y los movimientos de mestizaje o hibridación que se están multiplicando en nuestra sociedad solo están desarrollando una tendencia relativamente reciente y fructífera. Es, sin duda, una de las formas de expresión y representación de esas identidades culturales que se recomponen hoy y que corresponden a lo que el escritor caribeño Edouard Glissant llamó la «creolización del mundo» que juzga, por su parte, irreversible. Vemos el surgimiento, no de una identidad fija o congelada, sino más bien de una identidad que llega a usar un lenguaje extraño. Como es el caso del escritor argelino Aziz Chouaqui, que reconoce que no escribe ni en árabe clásico ni en francés académico, ni en lengua amazigh, sino en un idioma que reivindica como «hybride, violent, mosaïque» (Chouaqui, 2004:31). 
${ }^{6}$ "A veces mi madre reprocha la supremacía del «roumi», francés, en casa. Pero así fue, vine aquí a los cinco años, siempre hablé este idioma, es el que se impuso, y eso es todo. Le doy esta respuesta un tanto fatalista, ella se retira rápidamente, el debate termina. Pero estoy mintiendo, lo sé. Miento. Porque la verdad es que el árabe, o más bien el argelino, es, para mí, el idioma de lo prohibido. El lenguaje de «haram», pecado, esta palabra que florece con nosotros, es decir, desde nuestro nacimiento como una niña pequeña. Todas las niñas musulmanas podrían tener esta palabra como segundo nombre. «Haram», carne de cerdo, alcohol, cigarrillos, niños, maquillaje, minifalda, guateques, casarse con un francés. Algunos de estos «harams» son indiscutibles para mí: carne de cerdo, alcohol, está bien». (Belhaddad, 2001:58)

7 «El idioma argelino es también el de la violencia. No me mece nunca, como en mis primeros años, cuando mi niñera hacía con el árabe aromas de jardín. Pero mi niñera ya no está a mi lado y, desde entonces, este lenguaje estridente y cotidiano solo emite, la mayoría de las veces, prohibiciones o amenazas. (...) El idioma árabe, en este período, es como la palabra Argelia: engorroso, difícil, vergonzoso también cuando cualquier payaso de la escuela se cree irresistible al imitarlo como vomitar, escupir "rhâ, hâ", como si estas consonantes guturales forzaran los límites del palacio, sin halagarlo nunca. Sin embargo, no puedo prescindir de él. Este es el lenguaje interno, ¿cómo puedo separarme de mí mismo? Estoy inventando otro. La del yo intermedio. Un fifty-fifty. Media palabra, como llamamos a los hijos de matrimonios mixtos para resumir la mitad de Francia y la de Argelia. Con mis hermanas, puntúo mis frases con palabras que, por sí mismas, resumen un estado mental completo: "Zamaa", por ejemplo, imposible de traducir, "supuestamente", "Yainé", también sin traducción. Hubiera pagado, entonces, para que esta mezcla fuera, como hoy, una moda. En lugar de bajeza, los nombres de "makrout, baklaoua" fueran, por el contrario, tan dulces como los pasteles que designaban. Es terrible no vivir en el idioma de sus padres. Tan terrible como salir de su país». (Belhaddad, 2001:61-62)

${ }^{8}$ «Hace mucho tiempo que espero ese momento: poder sentarme en mi mesa de trabajo (una pequeńa mesa tambaleante bajo un mango, al fondo del patio) para hablar de Haití tranquilamente, despacio. Y lo que es aún mejor: hablar de Haití en Haití. No escribo, hablo. Escribimos con la mente. Hablamos con el cuerpo. Siento este país físicamente. Hasta el talón. Reconozco, aquí, cada sonido, cada grito, cada risa, cada silencio. Estoy en casa, no muy lejos del ecuador, en esta roca al sol a la que se aferran más de siete millones de hombres, mujeres y niños hambrientos, atrapados entre el mar Caribe y la República Dominicana (el enemigo ancestral). Estoy en casa con esta música de moscas verdes trabajando el cuerpo de este perro muerto, a unos metros del mango. Estoy en casa con esta chusma que se come unos a otros como perros rabiosos. Estoy instalando mi viejo Remington en este barrio popular, en medio de esta multitud sudorosa. Multitud gritona. Sin embargo, esta cacofonía incesante, este trastorno permanente, lo siento hoy, la he echado de menos en los últimos años. Recuerdo que cuando salí de Haití hace veinte 
ańos, estaba perfectamente feliz de escapar del estruendo que comienza al amanecer y termina tarde en la noche. Hay silencio en Puerto Príncipe solo entre la una y las tres de la mańana. La hora de los valientes. La vida solo puede ser pública en esta metrópoli asombrosamente superpoblada (una ciudad construida para apenas doscientos mil habitantes que hoy se encuentra con casi dos millones de histéricos). Hace veinte años, yo quería silencio y privacidad. Hoy, no puedo escribir si no siento a las personas que me rodean, listas para intervenir en cualquier momento en mi trabajo para darle otra dirección. Escribo al aire libre entre los árboles, la gente, llora, llora. En el corazón de esta energía caribeña. Con un recipiente con agua limpia, no muy lejos, para refrescar mi cuerpo (cara y torso) cuando la atmósfera se vuelve insoportable. Parece irrespirable. El agua brota por todas partes. Producto raro. Después de este breve baño, vuelvo a grandes pasos a mi tambaleante mesa para volver a teclear como loco en esta máquina de escribir que nunca dejé desde mi primer libro. Una pareja de siempre. Hemos pasado por tiempos difíciles, cariño. Días buenos. Días malos. Noches febriles. Curiosamente, es una máquina que me ha permitido expresar mi rabia, mi dolor o mi alegría. No creo que sea solo una máquina. A veces la escucho gemir cuando siente que estoy triste, o rechinar los dientes cuando escucha mi ira. Escribo todo lo que veo, todo lo que oigo, todo lo que siento. Un verdadero sismógrafo. De repente, levanto la Remington con el brazo extendido hacia el cielo despejado y duro del mediodía. Escribe más rápido, siempre más rápido. No es que tenga prisa. Estoy ocupado como un loco, cuando todo a mi alrededor va tan lento. Apenas estoy terminando una historia cuando surge otra. El desbordamiento. Escucho a la vecina explicarle a mi madre que ella sabe que lo tiene este tipo de enfermedad.

—Sí, querida, desde que llegó, se ha pasado el tiempo escribiendo en esta máquina maldita.

-Dice, dice la vecina, que esta enfermedad solo afecta a personas que han vivido demasiado tiempo en el extranjero.

- ¿Se ha vuelto loco? pregunta mi madre con ansiedad.

—No. Simplemente necesita volver a aprender cómo respirar, sentir, ver, tocar las cosas de manera diferente.

La vecina agrega que conoce un remedio que podría ayudarme a volver a un ritmo normal. No quiero un té calmante. Quiero perder la cabeza. Volver a ser un niño de cuatro ańos. Mira, un pájaro cruza mi campo de visión. Yo escribo: pájaro. Un mango cae. Yo escribo: mango. Los niños juegan a la pelota en la calle entre los autos. Escribo: niños, pelota, autos. Es como si fuera un pintor primitivo. Ahí está, lo encontré. Soy un escritor primitivo». (Laferrière, 1997:11-14)

${ }^{9}$ «El destino significó que, desde cierto punto de mi vida, me convertí en portador de dos idiomas, chino y francés. ¿¿Se debió enteramente al destino? ¿A menos que haya manifestado también una voluntad deliberada? El hecho es que traté de asumir el desafío asumiendo, a mi manera, los dos idiomas, hasta el punto de sacar las consecuencias extremas. Dos idiomas complejos, comúnmente conocidos como "grandes", cargados de historia y cultura. Y, sobre todo, dos idiomas de una naturaleza tan 
diferente que amplían la mayor brecha entre ellos que uno pueda imaginar. Esto significa que, durante al menos dos décadas después de mi llegada a Francia, mi vida ha estado marcada por un drama apasionado hecho sobre todo de contradicciones y desgarros. Estos, sin embargo, se transformaron gradualmente en una búsqueda no menos apasionada cuando finalmente opté por uno de los dos idiomas, adoptándolo como una herramienta creativa, sin eliminar por completo la otra, la llamada lengua materna. Silenciada, por así decirlo, esta última se ha transformado en un interlocutor fiel pero discreto, tanto más eficiente que sus murmullos, alimentando mi inconsciente, me proporcionaban constantemente imágenes para transformar, nostalgia para subsanar. No es sorprendente que desde entonces, en el corazón de mi aventura lingüística orientada hacia el amor por un idioma adoptado, presida orgullosamente un tema principal: el diálogo. Este tema iluminó mi largo recorrido; me brindó muchas ocasiones de júbilo y deleite cada vez que la simbiosis buscada pacientemente se realizaba como si fuera un milagro, una simbiosis que, al final, me llevó y continúa llevándome mucho más allá de lo que yo podía sospechar al principio». (Cheng, 2002:7-8)

${ }^{10}$ Télérama, n 2630, 07/06/2000. «Escribí en francés, pero con esa vacilación que hace que el idioma árabe esté allí, abajo, que empuja, que acelera el ritmo y que, finalmente, da algo nuevo».

\section{Referencias bibliográficas}

Alexakis, V. (1996). La Langue maternelle. Le Livre de Poche, $\mathrm{n}^{\circ} 14038$. Alexakis, V. (2002). Les mots étrangers. Stock.

Belhaddad, S. (2001). Entre-deux Je. Mango Document.

Chamoiseau, P. (1997). Écrire en pays dominé. Gallimard Folio, nº 3677.

Cheng, F. (2002). Le dialogue. Desclée de Brouwer.

Chouaki, A. (2018). Baya. Laphomic, 1989.

Chouaki, A. (2004, 11 de noviembre). «Portrait». Le Monde. P. 31

Chouaki, A. (1989). Saint-Pourçain-sur-Sioule: Bleu autour.

Chouaki, A. (1998). Les oranges. Mille et une nuits.

Del Castillo, M. (2000). L'adieu au siècle, Journal de l'année 1999. Seuil.

Derrida, J. (1996). Le monolinguisme de l'autre. Galilée.

Djebar, A. (2003). La disparition de la langue française. Albin Michel. Goldschmidt, G.A. (2000). La traversée des fleuves. Seuil.

Goldschmidt, G.A. (2004) Le poing dans la bouche. Verdier.

Hagège, C. (2000). Halte à la mort des langues. Éditions Odile Jacob, 2000.

HaGÈGe, C. (2006). Combat pour le français: au nom de la diversité des langues et des cultures. Odile Jacob.

Huston, N. (1999). Nord perdu. Actes Sud.

Laferrière, D. (1997). Pays sans chapeau. Le Serpent à Plumes.

MaAlouf, A. (1998). Identités meurtrières. Grasset.

Maalouf, A. (2004). Origines. Grasset. 
Idiomas cruzados · J.-P. Castellani

Sebbar, L. (2003). Je ne parle pas la langue de mon père. Julliard.

Sebbar, L. (2004). Mes Algéries en France. Bleu autour.

Todorov, T. (1989). Nous et les autres. Seuil.

Todorov, T. (1996). L'homme dépaysé. Seuil.

Todorov, T. (2002). Devoirs et délices, une vie de passeur. Seuil.

Vila-Matas, E (2002, 14 de septiembre). ¿Por qué es usted tan moderno? Babelia, El País. 